\title{
Genotype by environment (climate) interaction improves genomic prediction for production traits in US Holstein cattle
}

\author{
F. Tiezzi, ${ }^{* 1}$ G. de los Campos, $†$ K. L. Parker Gaddis, $\ddagger$ and C. Maltecca* \\ *Department of Animal Science, North Carolina State University, Raleigh 27695 \\ †Department of Epidemiology and Biostatistics, Michigan State University, East Lansing 48828 \\ ‡Council on Dairy Cattle Breeding, Bowie, MD 20716
}

\begin{abstract}
Genotype by environment interaction $(\mathrm{G} \times \mathrm{E})$ in dairy cattle productive traits has been shown to exist, but current genetic evaluation methods do not take this component into account. As several environmental descriptors (e.g., climate, farming system) are known to vary within the United States, not accounting for the G $\times \mathrm{E}$ could lead to reranking of bulls and loss in genetic gain. Using test-day records on milk yield, somatic cell score, fat, and protein percentage from all over the United States, we computed within herd-year-season daughter yield deviations for 1,087 Holstein bulls and regressed them on genetic and environmental information to estimate variance components and to assess prediction accuracy. Genomic information was obtained from a 50k SNP marker panel. Environmental effect inputs included herd (160 levels), geographical region (7 levels), geographical location (2 variables), climate information (7 variables), and management conditions of the herds (16 total variables divided in 4 subgroups). For each set of environmental descriptors, environmental, genomic, and $\mathrm{G} \times \mathrm{E}$ components were sequentially fitted. Variance components estimates confirmed the presence of $\mathrm{G} \times \mathrm{E}$ on milk yield, with its effect being larger than main genetic effect and the environmental effect for some models. Conversely, $\mathrm{G} \times \mathrm{E}$ was moderate for somatic cell score and small for milk composition. Genotype by environment interaction, when included, partially eroded the genomic effect (as compared with the models where $\mathrm{G} \times \mathrm{E}$ was not included), suggesting that the genomic variance could at least in part be attributed to $\mathrm{G} \times \mathrm{E}$ not appropriately accounted for. Model predictive ability was assessed using 3 crossvalidation schemes (new bulls, incomplete progeny test, and new environmental conditions), and performance
\end{abstract}

Received June 1, 2016.

Accepted November 4, 2016.

${ }^{1}$ Corresponding author: f_tiezzi@ncsu.edu was compared with a reference model including only the main genomic effect. In each scenario, at least 1 of the models including $\mathrm{G} \times \mathrm{E}$ was able to perform better than the reference model, although it was not possible to find the overall best-performing model that included the same set of environmental descriptors. In general, the methodology used is promising in accounting for $\mathrm{G} \times \mathrm{E}$ in genomic predictions, but challenges exist in identifying a unique set of covariates capable of describing the entire variety of environments.

Key words: genotype by environment interaction, genomic prediction, reproducing kernel Hilbert space regression, reaction norm model

\section{INTRODUCTION}

Dairy cattle breeding programs have ensured an improvement of performance over the past decades within the United States (CDCB, 2016). Phenotypes for productive, reproductive, and type traits recorded over a wide variety of environments are currently used in the estimation of breeding values for selection candidates. Selection has been traditionally based on BLUP and pedigree information, but BLUP accuracy in predicting breeding values has received a considerable boost from the availability of genomic information coming from low-cost genotyping assays (Hayes et al., 2009). Yet, genomic information represents a promising tool to improve the efficiency of selective breeding in dairy cattle when bulls' daughter information is not available.

Statistical models for the prediction of breeding values assume the phenotype (i.e., the individual measure of a trait on an individual, for example milk yield) as the sum of 2 main components, the additive genetic and environmental effects. In this model, the single gene variants that an individual carries determine its genetic potential and the environmental conditions (defined as the management, nutrition, and climatic conditions where the individual expresses its genetic potential) determines the mean performance of individuals in a given environment, independent of the genetic makeup. 
This approach ignores genotype by environment interaction $(\mathbf{G} \times \mathbf{E})$ and may not be well-suited for selection targeting specific environmental conditions.

The existence, magnitude, and genetic architecture of $\mathrm{G} \times \mathrm{E}$ for breeding goals in dairy cattle populations have been investigated by several authors (Shariati et al., 2007; Hayes et al., 2009; Strandberg et al., 2009), and what emerges is that $\mathrm{G} \times \mathrm{E}$ has an effect on most breeding goal traits in dairy cattle. Several authors have proposed strategies to account for $\mathrm{G} \times \mathrm{E}$ in dairy cattle genetic evaluation and breeding scheme design (Kolmodin and Bijma, 2004; Bryant et al., 2005; Mulder et al., 2006). When environmental conditions are stable but far from optimal values (e.g., excessive temperature and humidity throughout the year), breeders can develop specialist strains (Kassen, 2002) adapted to these extreme environments (e.g., hot and humid). On the other hand, when conditions are unstable (e.g., diet in pasture-based systems), breeders can develop robust generalist individuals that are capable of maintaining constant performance over different environmental conditions.

Some of these strategies have already been implicitly implemented in different dairy breeds and selection programs. Bryant et al. (2006) defined the US Holstein as a specialist of superior feeding level, whereas New Zealand Holstein and Jersey are considered generalists because they are more tolerant to changes in environmental conditions. This hypothesis is supported by the work of Kolmodin et al. (2003), who showed that selection of genotypes that are top-performing in specific environments increases their environmental sensitivity, as gene variants that perform well in that environment can reach fixation, leaving individuals and the population without the genetic background needed to tolerate environmental changes. Performance of specialized breeds, such as the US Holstein, could be particularly threatened by changes in environmental conditions, especially with the more frequent occurrence of heat stress due to global warming (Hayes et al., 2009). In the next decade livestock will be facing new climatic conditions and, inevitably, different management systems. In the presence of $\mathrm{G} \times \mathrm{E}$, current breeding goals might not be appropriate to the future industry (Ravagnolo and Misztal, 2000). Breeding programs should therefore either consider robustness as a breeding goal or redefine the breeding goals for future industry needs; both approaches require modeling $\mathrm{G} \times \mathrm{E}$.

The statistical treatment of $\mathrm{G} \times \mathrm{E}$ in genetic evaluations hinges on 2 different approaches (Windig et al., 2011). The first and classical approach is to consider performance in the different environments as different, potentially correlated, traits. This approach is used in across-country genetic evaluations (Schaeffer, 1994;
Nilforooshan et al., 2010, 2014) and yields environment (country)-specific predictions of breeding values. The extent of $\mathrm{G} \times \mathrm{E}$ is quantified by means of the genetic correlations across environments. The second approach considers the use of environmental parameters (EnCov), which are covariates that link the different environments (Ravagnolo and Misztal, 2000; Bohmanova et al., 2008; Su et al., 2009). Using this approach, breeding values are estimated for overall performance (i.e., across environments) and for the sensitivity of each individual to the changes in EnCov, also known as reaction norm. The latter approach has been demonstrated by Calus et al. (2004) to be more suitable for genetic evaluations, as it combines observations in larger groups and provides better parameter estimation, although the EnCov might not catch part of the $\mathrm{G} \times \mathrm{E}$. Nonetheless, the choice of a set of EnCov that explains the entire G $\times \mathrm{E}$ is not trivial, leading to the necessity of testing several EnCov in each population under study (Calus and Veerkamp, 2003; Zwald et al., 2003).

In spite of this, the reaction norm model remains a powerful and flexible approach for modeling $G$ $\times \mathrm{E}$; however, implementing a reaction norm model with many genetic markers and many EnCov is not trivial. Recently, Jarquín et al., (2014) proposed an approach that allows modeling interactions between large numbers of SNP and large numbers of EnCov using Gaussian processes, and Pérez-Rodriguez et al., (2015) extended the implementation to accommodate pedigree. The methodology proposed by Jarquín et al. (2014) falls within the class of Reproducing Kernel Hilbert Space regressions, which in animal breeding have been considered for genomic prediction (Gianola and van Kaam, 2008; de los Campos et al., 2009). Compelling features of these models include the possibility of including genomic markers to account for genetic effect and using this information in interaction with environment, even defining complex variance-covariance structures spanning several EnCov and grouping variables (i.e., categories).

The genotyped US Holstein reference population allows genomic selection to leverage phenotypic information recorded on daughters across the whole country (i.e., under a wide range of environmental conditions). Genomic prediction can be performed using models that include reaction norms over several EnCov.

The objectives of our study were to (1) assess the effect of genotype, environment, and their interaction on US Holstein performance across the United States, (2) test the predictive ability of models that incorporate $\mathrm{G} \times \mathrm{E}$ for prediction of daughters' performance for progeny testing bulls, and (3) test predictive ability when the validation set consists of performance under new climatic conditions. 


\section{MATERIALS AND METHODS}

\section{Data}

Test-day data files containing cow production information from DRMS (Dairy Records Management System, Raleigh, NC) were accessed (https://www.cdcb. us/CF-RCS/GetRCS.cfm?DocType=formats\&DocNa $\mathrm{me}=\mathrm{fmt} 4 . \mathrm{html}$ ) and used to create the database used in this study. A total of 22,593,022 test-day records from 1,036,040 cows, daughters of 33,404 bulls, were included. Recordings for milk yield (MY) and SCS were used as phenotypes. Fat (FP) and protein percentages $(\mathbf{P P})$ were calculated by dividing the respective yields by milk yield and used as phenotypes, instead of using the respective total daily yield. This was done because the content (percentages) of fat and protein present a relatively oligo-genic architecture as compared with the total yield (VanRaden et al., 2009); for instance, FP is known to be strongly associated with the DGAT1 locus located on chromosome 14 (Kühn et al., 2004).

\section{Step 1: Computation of Daughter Yield Deviations}

We first used DRMS data to compute herd-yearseason daughter yield deviations (hysDYD) using the following model

$$
\begin{gathered}
y_{i j k l m}=\mu+\text { parsolmf }_{i}+\text { hys }_{j}+\text { cowlact }_{k l} \\
+ \text { addgen }_{l}+\varepsilon_{i j k l m},
\end{gathered}
$$

where $y_{i j k l m}$ is a phenotypic measure (MY, SCS, FP or $\mathrm{PP}), \mu$ is the overall mean, parsolmf $f_{i}$ is the fixed effect of the $i$ th class of parity (1st, $2 \mathrm{nd}, 3 \mathrm{rd},>3 \mathrm{rd}$ ) by stage of lactation (forty 15-d classes) by milking frequency (2 or 3 times per day), $h y s_{j}$ is the random effect of the $j$ th herd-year-season class (where seasons were defined as 3-mo periods: January to March, April to June, July to September, October to December), cowlact $_{k l}$ is the permanent environmental random effect of the $k$ th lactation of the lth cow, addgen $n_{l}$ is the additive genetic effect of the lth cow, and $\varepsilon_{i j k l m}$ is a random residual. Best linear unbiased estimates (BLUE) of fixed effects and BLUP of random effects were obtained using variance components estimated on the present data and reported in Supplemental Table S1 (https://doi. org/10.3168/jds.2016-11543). The model of expression [1] was fitted using the BLUPf90 family of programs (Misztal et al., 2002), we first used GIBBS2f90 for the estimation of variance components, BLUPf90IOD2 to obtain BLUE and BLUP solutions, and ACCf90 for obtaining EBV reliabilities.
Using estimates and predictions from the model described above, we derived hysDYD, which expressed the average adjusted performance of the daughters of a bull in a given herd-year-season contemporary group. We computed hysDYD for each sire as

$$
\operatorname{hysDYD}_{i j}=\operatorname{addgen}_{i}+\text { hys }_{j}+\varepsilon_{i j} \text {, }
$$

where hysDYD $i j$ is the DYD for the $i$ th bull in the $j$ th herd-year-season (HYS), hys $s_{j}$ is the effect of the $j$ th HYS, addgen $i$ is the genetic effect of the ith bull's daughters, and $\varepsilon_{i j}$ is the average residual from model [1] for daughters of sire $i$ in herd-year-season group $j$. The hysDYD were then weighted for the respective within-HYS effective daughters contribution, which accounted for the contemporary group (HYS) structure of the bull's daughters, the correlation between the same observation of the bull's daughters, and the reliability of the performance of the daughters' dam (Fikse and Banos, 2001).

\section{Step 2: Genotype by Environment Analysis}

Only bulls with Illumina 50k Beadchip (San Diego, $\mathrm{CA}$ ) genotypes were included for the $\mathrm{G} \times \mathrm{E}$ analysis. Markers were edited for call rate (removed if lower than $90 \%$ ) and minor allele frequency (removed if lower than $5 \%$ ). This generated 1,500,119 hysDYD observations linked to bulls with genotypes. To reduce computational costs while maintaining a meaningful representation of all bulls and environment across the country, further editing was applied in 2 steps. In step one, hysDYD were excluded if showing a value of effective daughters contribution smaller than 3 for any traits and if distance between the herd and the closest weather station was larger than $100 \mathrm{~km}$. Herds were removed when only having a single HYS block. In step 2, we aimed to maximize the number of states and seasons represented for each sire. The hysDYD were edited to constrain the number of herds used per state while having a continuative presence of the chosen herd across seasons. As larger farms were more likely to be picked, we repeated this step, creating 3 subsets by splitting herds based on the number of cows sampled in a single test-day, with classes being less than 100 cows, between 100 and 1,000 and more than 1,000 cows. After editing, we had 16,664 hysDYD from 82,495 cows, daughters of 1,087 bulls, recorded in 1,875 HYS classes from 160 herds located in 36 states across the United States. Median (minimum, maximum) count of records for sire, HYS, and herd number of hysDYD were $8(3,165), 7(3,67)$, and 67 $(3,571)$, respectively. States were further grouped into 


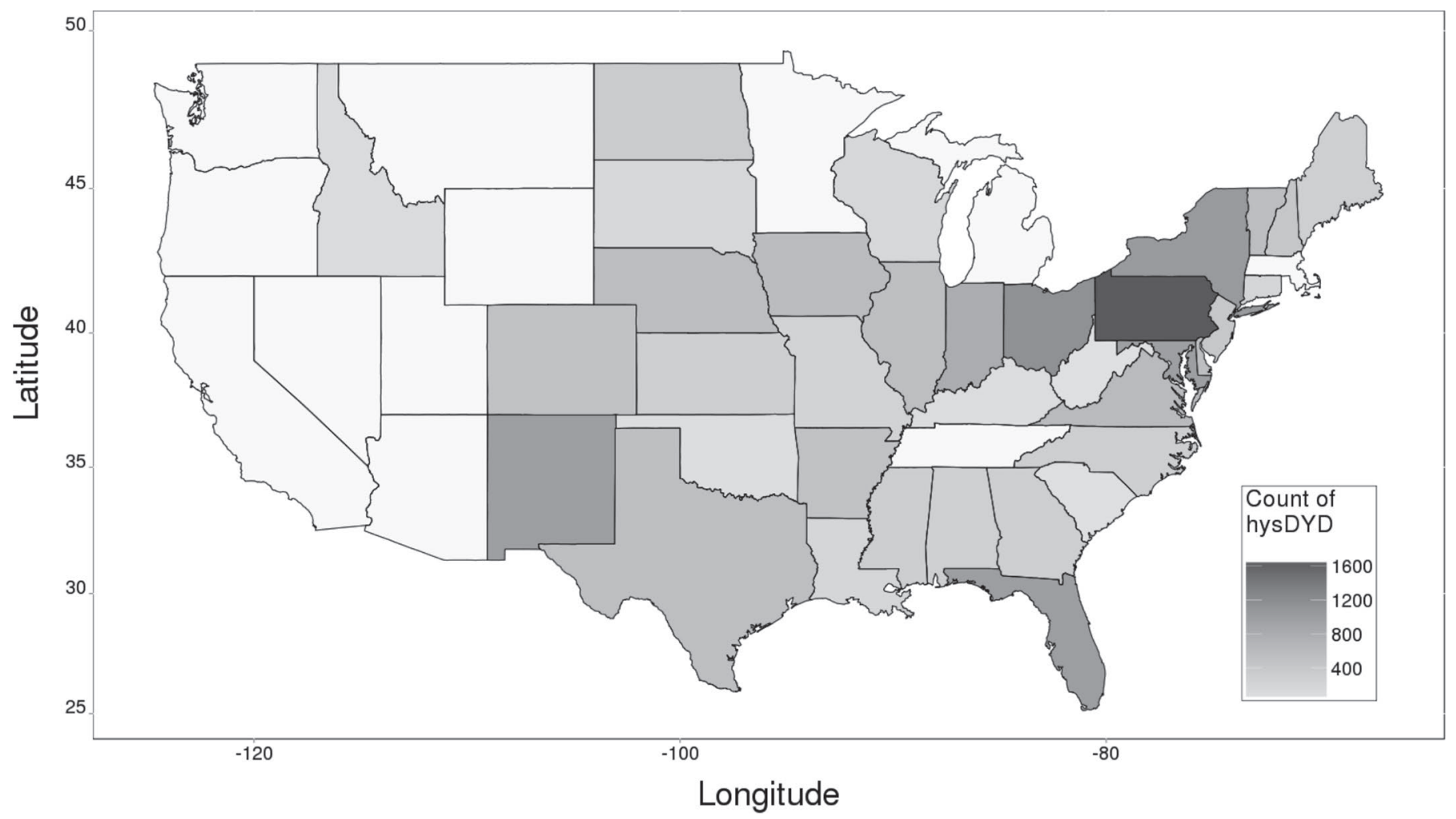

Figure 1. Frequency of observations across the country. hysDYD = herd-year-season daughter yield deviations.

7 different regions within the United States [Northeast (I: CT, DE, MA, MD; II: ME, NH, NJ, NY, VT), East (I: OH, PA; II: VA, WV), Southeast (AL, FL, GA, LA, MS, NC, SC), Midwest (I: WI, IL, IN, MI, NE, MO, IA; II: KS, OK, AR, KY), Southwest (NM, TX), North (ND, SD, MN, MT), and West (CO, WA, OR, ID)]. The distribution of records over states of the country is reported in Figure 1.

Environmental Parameters. Following the work of Parker Gaddis et al. (2016), we used geographical location, weather data, and information from DRMS herd summaries to describe environmental conditions. We computed a total of 25 environmental covariates (Table 1). Latitude and longitude (hereafter denoted as L) of the herd location were used for geo-referencing. Weather records (hereafter denoted as W) were obtained from the National Climatic Data Center Quality Controlled Local Climatological Data (https://www. ncdc.noaa.gov/qclcd/QCLCD?prior $=$ N) database at the National Oceanic and Atmospheric Administration. Using zip codes, we derived geographical coordinates and matched them to the closest weather station, this was done using the packages "zipcode" (Breen, 2012) and "geosphere" (Hijmans et al., 2012) in R (R Core Team, 2014). The assignment of weather stations to farms was done ensuring that the distance between the central zip code location and the station was not larger than $100 \mathrm{~km}$. Weather conditions were described using the average, minimum, and maximum daily temperature, relative humidity, atmospheric pressure, and wind speed; for rainfall, we used the total monthly precipitation. All these variables were calculated by weather station and then merged to the hysDYD records.

A generic herd size and management profile per HYS class (hereinafter denoted as $\mathbf{M}$ ) was created using testday datafile information. We aimed at creating subsets of variables that could group the herds into different farming systems; therefore, we arbitrarily characterized the herd for size (number of cows), breed composition (percentage of Holstein cows over total), and milking management (number of milking times per day). Herd profile was refined using information on specific farming choices, extracting information from the DRMS herd summary. A first set of variables aimed at characterizing the herd for service sire choice (percentage of proven sires over total, percentile of genetic merit for proven sires, percentile of genetic merit for young sires; here called $\mathbf{S}$ ). A second set of variables was defined to characterize the herd level of fertility (days from calving to first service, calving interval, conception rate; called $\mathbf{F}$ ) and culling practices defined based on culling reasons (low production, reproduction, mastitis, feet 
and legs, injury, disease, death; called C). Herd management parameters, as defined in $\mathrm{S}, \mathrm{F}$, and $\mathrm{C}$, were herd averages over the entire period studied. In addition to the EnCov, we used the herd and geographical region to group the observations (these groupings will hereby referred to as $\mathbf{H}$ and $\mathbf{R}$, respectively).

Statistical Models. Our baseline model (hereafter referred to as the genomic model) consisted of a standard genomic-BLUP regression of hysDYD on genotype data. The model was defined as follows

$$
\operatorname{hysDYD}_{i j}=\mu+g_{i}+\varepsilon_{i j}
$$

where hysDYD $i j$ represents the hysDYD of the $i$ th bull in the $j$ th HYS, $\mu$ is the overall mean, $g_{i}$ is the additive genetic effect of the $i$ th bull, and $\varepsilon_{i j}$ is random residual. The distribution of the random terms in the right-hand-side of expression [3] was

$$
\varepsilon_{i j} \sim \operatorname{IID} N\left(0, \sigma_{\varepsilon}^{2}\right)
$$

and

$$
\mathbf{g} \sim N\left(0, \mathbf{Z G} \mathbf{Z}^{\prime} \sigma_{g}^{2}\right)
$$

where IID stands for independent and identically distributed, $\sigma_{\varepsilon}^{2}$ is the residual variance, $\sigma_{g}^{2}$ is a total genomic variance, $\mathbf{g}$ is the vector of additive genomic values, $\mathbf{Z}$ is a sire incidence matrix, and $\mathbf{G}$ is the genomic relationship matrix built on marker information (VanRaden, 2008).

Our second model was a random regression on environmental covariates. The EnCov are summarized in Table 1. For the $\mathrm{R}$ and $\mathrm{H}$ effects, as well as for each group of EnCov, 3 models were tested. The first model included the environmental effect only:

\begin{tabular}{|c|c|c|c|c|}
\hline Item & Mean & SD & Minimum & Maximum \\
\hline \multicolumn{5}{|l|}{ Productive traits } \\
\hline Milk yield, $\mathrm{kg}$ & 0.0 & 17.18 & -115.11 & 92.49 \\
\hline Fat percentage, $\%$ & 0.0 & 14.82 & -89.26 & 120.17 \\
\hline Protein percentage, $\%$ & 0.0 & 5.41 & -34.9 & 30.13 \\
\hline $\mathrm{SCC}$ & 0.0 & 34.17 & -213.53 & 301.97 \\
\hline \multicolumn{5}{|l|}{ Geographical coordinates } \\
\hline Latitude, degrees & 38.96 & 4.22 & 28.57 & 46.43 \\
\hline Longitude, degrees & -85.32 & 10.36 & -114.46 & -69.69 \\
\hline \multicolumn{5}{|l|}{ Herd size and management descriptors } \\
\hline Number of heads, no. & 712.78 & 694.02 & 9 & 3,536 \\
\hline Percentage Holstein cows & 95.8 & 0.1 & 0.1 & 1 \\
\hline Milkings per day, no. & 2.54 & 0.48 & 2 & 3 \\
\hline \multicolumn{5}{|l|}{ Herd fertility descriptors } \\
\hline Days to first service & 81.93 & 15.43 & 58.08 & 143.43 \\
\hline Calving interval, mo & 13.95 & 0.69 & 12.72 & 16.85 \\
\hline Conception rate, $\%$ & 32.06 & 7.6 & 17.92 & 88 \\
\hline \multicolumn{5}{|l|}{ Service sire choice descriptors } \\
\hline Proven sires over total sires, $\%$ & 65.09 & 19.25 & 0.61 & 100 \\
\hline Proven sires PTA, percentile & 60.2 & 14.42 & 15.77 & 90.93 \\
\hline Young sires PTA, percentile & 60.88 & 18.05 & 0 & 86.33 \\
\hline \multicolumn{5}{|l|}{ Culling descriptors } \\
\hline Culling due to low production, $\%$ & 11.3 & 9.15 & 0 & 46.04 \\
\hline Culling due to poor fertility, $\%$ & 15.4 & 10.68 & 1.5 & 58.27 \\
\hline Culling due to mastitis, $\%$ & 11.7 & 7.72 & 0 & 43 \\
\hline Culling due to feet and legs issues, $\%$ & 6.57 & 4.87 & 0 & 25.28 \\
\hline Culling due to general injury, $\%$ & 12.09 & 11.5 & 0.15 & 85.79 \\
\hline Culling due to general disease, $\%$ & 5.98 & 5.33 & 0 & 23.12 \\
\hline Died cows over total culled, $\%$ & 17.28 & 10.92 & 2.18 & 71.14 \\
\hline \multicolumn{5}{|l|}{ Climate variables } \\
\hline Maximum temperature,${ }^{\circ} \mathrm{C}$ & 18.59 & 9.39 & -5.5 & 35.67 \\
\hline Minimum temperature, ${ }^{\circ} \mathrm{C}$ & 6.96 & 8.81 & -16.5 & 24.13 \\
\hline Average temperature, ${ }^{\circ} \mathrm{C}$ & 12.9 & 9.07 & -10.47 & 29.7 \\
\hline Relative humidity, $\%$ & 64.83 & 9.87 & 23.86 & 30.14 \\
\hline Pressure, $\mathrm{mmHg}$ & 28.91 & 1.46 & 0 & 24.37 \\
\hline Wind speed, $\mathrm{km} / \mathrm{h}$ & 11.39 & 3.64 & 20.82 & 92.72 \\
\hline Rainfall, mm & 235.6 & 130.25 & 0 & $1,751.58$ \\
\hline
\end{tabular}

Table 1. Descriptive statistics of the phenotypic data ${ }^{1}$ and environmental covariates ${ }^{2}$ used for the study (number of herd-year-season daughter yield deviation blocks was equal to 16,664 )

${ }^{1}$ Phenotypic data were productive traits.

${ }^{2}$ Environmental covariates were geographical coordinates, herd size and management descriptors, herd fertility descriptors, service sire choice descriptors, culling descriptors, and climate variables. 


$$
\operatorname{hysDYD}_{i j}=\mu+E_{j}+\varepsilon_{i j} \text {, }
$$

where $E_{j}$ is the random effect of the environmental conditions at the $j$ th HYS. The vector containing all the levels for this random effect were assumed to follow a normal distribution,

$$
\mathbf{E} \sim N\left(0, \mathbf{X X}^{\prime} \sigma_{E}^{2}\right)
$$

where $\mathbf{X X}^{\prime}$ is an environmental similarity matrix, $\mathbf{X}$ is a matrix containing all environmental descriptors, each centered to a null mean and a unit variance, and $\sigma_{E}^{2}$ is an environmental variance. The covariance $\mathbf{X} \mathbf{X}^{\prime}$ was scaled to have an average diagonal value of 1 ; therefore, the variance parameter $\sigma_{E}^{2}$ can be interpreted as the amount of variance of $y$ explained by the regression on environmental covariates.

In a third model we combined the genetic and environmental information in an additive fashion

$$
\operatorname{hysDYD}_{i j}=\mu+E_{j}+g_{i}+\varepsilon_{i j} \text {, }
$$

where elements are as defined above.

Finally, following Jarquín et al. (2014) we considered a model that included interactions between markers and environmental covariates. Because the number of markers and of environmental covariates was large, modeling all possible interactions between these 2 sets of predictors is not feasible; however, interactions can be modeled implicitly using covariance functions. Jarquínn et al. (2014) showed that the covariance function induced by a reaction norm model (Falconer, 1990) is simply the Hadamard (or cell-by-cell) product of the genomic and environmental similarity matrices. Therefore, in a third model we combined both main effects using

$$
\operatorname{hysDYD}_{i j}=\mu+E_{j}+g_{i}+g E_{i j}+\varepsilon_{i j} \text {, }
$$

where $g E_{i j}$ the interaction of the $i$ th bull at the $j$ th HYS, contained in vector $\mathbf{g E}$ and defined as

$$
\mathbf{g E} \sim N\left(0,\left[\mathbf{Z G Z}^{\prime \circ} \mathbf{X} \mathbf{X}^{\prime}\right] \sigma_{g E}^{2}\right),
$$

where $\sigma_{g E}^{2}$ is the variance of the genomic by environment interaction and $\mathbf{Z} \mathbf{G} \mathbf{Z}^{\prime \circ} \mathbf{X} \mathbf{X}^{\prime}$ indicates the Hadamard product of $\mathbf{Z} \mathbf{G} \mathbf{Z}^{\prime}$ and $\mathbf{X} \mathbf{X}^{\prime}$.

The models of expression [8] and [9] were defined using different sets of EnCov separately. Models that accounted for region cross-classified effects $(\mathbf{R})$ will be denoted as $\mathrm{R}, \mathrm{G}+\mathrm{R}$, and $\mathrm{G}+\mathrm{R}+\mathrm{G} \times \mathrm{R}$; those that accounted for herd $(\mathbf{H})$ will be denoted as $\mathrm{H}, \mathrm{G}+\mathrm{H}$, and $\mathrm{G}+\mathrm{H}+\mathrm{G} \times \mathrm{H}$. Similarly, models that accounted for the EnCov were identified with the respective EnCov-set name (e.g., models with L were called L, G $+\mathrm{L}$, and $\mathrm{G}+\mathrm{L}+\mathrm{G} \times \mathrm{L})$.

An additional model, used to assess the effects (random regression coefficients) of the EnCov, was defined as

$$
\operatorname{hysDYD}_{i j}=\mu+E_{j}+g_{i}+\varepsilon_{i j} \text {, }
$$

where $E_{j}$ is the environmental effect of all the EnCov fit as a set of random covariates and all other terms are as described above. Results from this part of the study will not be discussed, but are reported as supplementary material (Supplemental Figure S1; https://doi. org/10.3168/jds.2016-11543).

Analyses were performed using the BGLR R-package (Janss et al., 2012; Jarquín et al., 2014; Pérez and de los Campos, 2014). The Markov chain-Monte Carlo algorithm was run for 42,000 iterations, with 2,000 iterations discarded as burn-in, and estimates were derived using a thinning interval of 5 iterations. Convergence of the models was assessed by visual inspection of trace plots and post-Gibbs analyses using the $\mathrm{R}$ package CODA (Plummer et al., 2006).

\section{Cross-Validation}

A cross-validation scheme was designed using 3 criteria.

New Bulls. Bulls that had at least 50 hysDYD were randomly assigned to 4 folds and masked successively, simulating prediction of daughters' performance for bulls that were not progeny-tested in the United States (Table 2). Predictive ability of the models was averaged across the 4 folds.

Incomplete Progeny Testing. The objective of this second cross-validation was to evaluate the pre-

Table 2. Number of records masked (proportion to the total data set) for each split used in the cross-validation

\begin{tabular}{lccrr}
\hline Item & Fold 1 & Fold 2 & Fold 3 & \multicolumn{1}{c}{ Fold 4} \\
\hline New bulls & $679(4 \%)$ & $981(6 \%)$ & $1,371(8 \%)$ & $1,516(9 \%)$ \\
Incomplete progeny test & $217(1 \%)$ & $185(1 \%)$ & $195(2 \%)$ & $815(5 \%)$ \\
\hline
\end{tabular}


Table 3. Number of records masked (proportion to the total data set) for each split and fold used in the cross-validation

\begin{tabular}{llc}
\hline Region & States included & Number of records (\%) \\
\hline Northeast I & CT, DE, MA, MD & $1,727(10)$ \\
Northeast II & ME, NH, NJ, NY, VT & $2,709(16)$ \\
East I & OH, PA & $1,145(7)$ \\
East II & VA, WV & $2,266(14)$ \\
Southeast & AL, FL, GA, LA, MS, NC, SC & $2,370(14)$ \\
Midwest I & WI, IL, IN, MI, NE, MO, IA & $2,856(17)$ \\
Midwest II & KS, OK, AR, KY & $952(6)$ \\
Southwest & NM, TX & $1,541(9)$ \\
North & ND, SD, MN, MT & $506(3)$ \\
West & CO, WA, OR, ID & $592(4)$ \\
\hline
\end{tabular}

diction accuracy that can be achieved on bulls that have progeny testing records from some regions. To this end, we randomly assigned records of a sire from different regions to folds. The composition of the 7 macro-regions is reported in Table 3. To have validation sets of comparable size, regions with large sample size were split into 2 subregions, generating a total of 10 subregions. Bulls with hysDYD in at least 4 regions were selected and randomly assigned to 4 folds. One region per bull was masked, simulating progeny-testing for bulls' progeny spread across the country but with daughters' information missing for some regions. This procedure was repeated for each fold and results (accuracies of prediction) were averaged.

Missing Region. Data from each of the 10 microregions were alternatively masked. This aimed at predicting daughters' performance under environmental conditions not found in the training set (i.e., potential new management and climatic conditions). Predictive ability of the models was averaged across the 10 folds. In addition, in an effort to simulate predictive ability when new conditions are equivalent to a warmer climate, we looked specifically at the predictive ability for the Southeast and Southwest regions.

Assessment of Predictive Ability. Predictive performance was measured using within-herd correlation between cross-validation predictions and observations. Repeating this for every trait and prediction model yielded (per herd) a Pearson's product-moment correlation estimate, $r_{j}$, and its sampling variance $(V)$, $V\left(r_{j}\right)=\frac{1-r_{j}^{2}}{n-2}$, where $n$ is the number of observations for that block. Then, a weighted across-blocks correlation $\left(r_{w}\right)$ was calculated using the formula

$$
r_{w}=\frac{\sum_{j=1}^{z} \frac{r_{j}}{V\left(r_{j}\right)}}{\sum_{j=1}^{z} \frac{1}{V\left(r_{j}\right)}},
$$

where $r_{j}$ is the intrablock correlation between $y$ and $\hat{y}$ for the $j$ th block, $V\left(r_{j}\right)$ is its variance, and $z$ is the number of blocks (herds) in that validation set. In the scenarios where several folds were involved (new bulls, incomplete progeny test, and missing region), $r_{w}$ across the folds were averaged (and standard deviation was computed) by model and trait and used for model evaluation.

\section{RESULTS AND DISCUSSION}

\section{Magnitude of the Genomic by Environment Interaction}

The proportion of variance components explained by the different effects is reported in Figure 2 and Supplemental Table S2 (https://doi.org/10.3168/jds.201611543). Genomic effect accounted for $28 \%$ of total variance for MY, and 24, 25, and 19\% for FP, PP, and SCS, respectively, when it was the only effect fitted in the model. To the best of our knowledge, no study has been conducted with US dairy cattle that estimated genomic effect on hysDYD. Nevertheless, if proportion of variance absorbed by the genomic effect is to be compared with the heritability of a trait, our results appear to be consistent with what was reported by VanRaden et al. (2009) in the US Holstein population.

When blocking factors $\mathrm{R}$ and $\mathrm{H}$ where included, the latter showed a stronger environmental effect: $\mathrm{H}$ accounted for approximately 50, 26, 16, and $33 \%$ of the total variance for MY, FP, PP, and SCS, respectively, compared with the $2,4,4$, and $8 \%$ accounted by $\mathrm{R}$ for the same traits. When fitted in conjunction with $\mathrm{G}$ (i.e., in $\mathrm{G}+\mathrm{R}$ and $\mathrm{G}+\mathrm{H}$ ), $\mathrm{R}$ and $\mathrm{H}$ contribution decreased compared with when they were fit as the only effect in the model. Null (close to zero) estimates of $G$ $\times \mathrm{E}$ were found fitting $\mathrm{G} \times \mathrm{H}$, yet sizable when $\mathrm{G} \times \mathrm{R}$ was included, with the latter accounting for 22 (MY), 16 (FP), 6 (PP), and 15\% (SCS) of the phenotypic variance. Farm geographical coordinates, as defined in L, accounted for smaller proportions of variance compared 

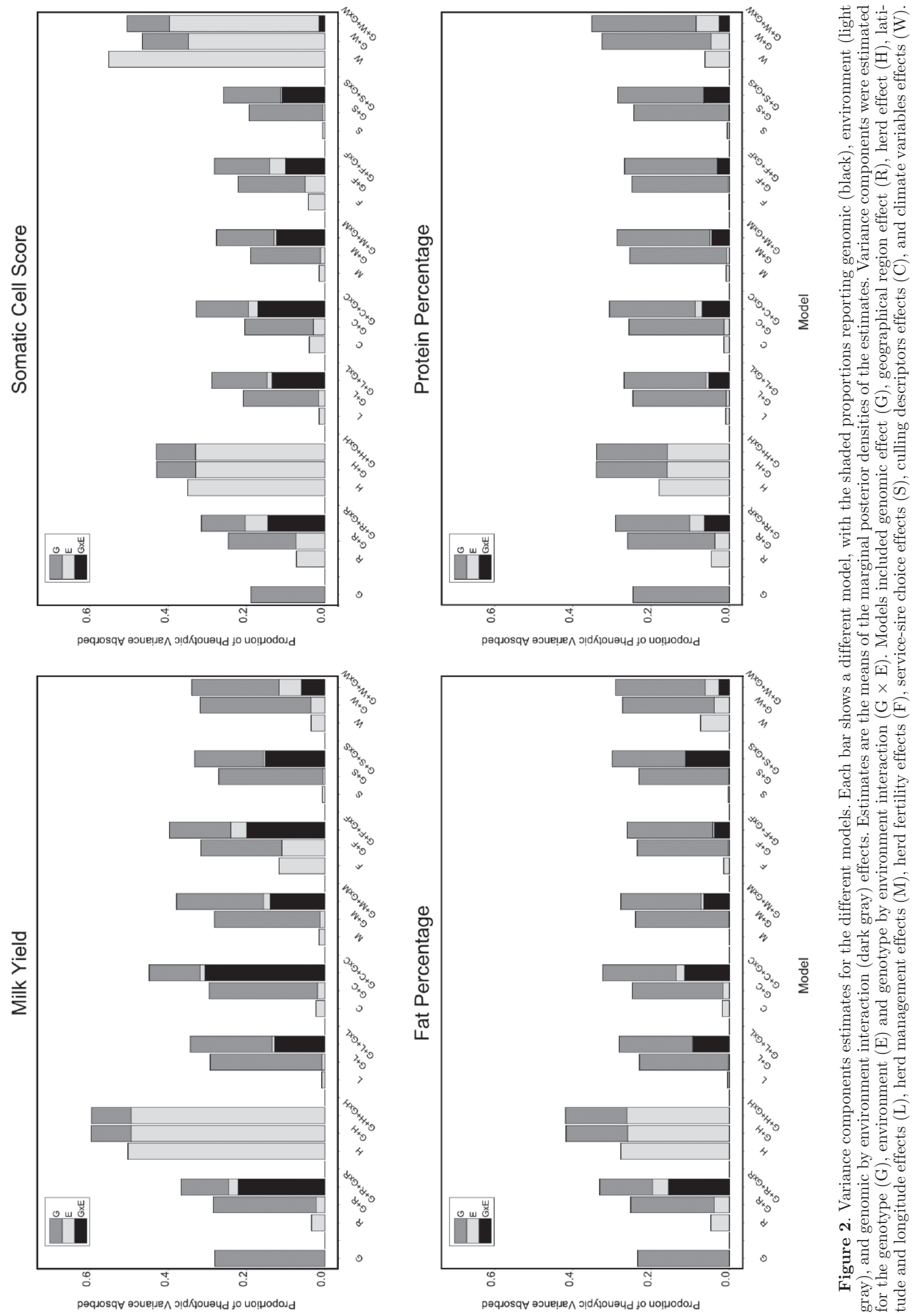
with the blocking factor $\mathrm{H}$, always having negligible effect (i.e., smaller than $2 \%$ ). Nevertheless, the proportion of $\mathrm{G} \times \mathrm{E}$ variance absorbed by model $\mathrm{G} \times \mathrm{L}$ was sizable $(13,9,5$, and $14 \%$ for $\mathrm{MY}, \mathrm{FP}, \mathrm{PP}$, and SCS, respectively), albeit always smaller than the variance absorbed by $\mathrm{G} \times \mathrm{R}$.

The proportion of variance absorbed by the different EnCov and their interaction with the genotype was heterogeneous across traits. For MY, the strongest environmental effect was found in models that considered $\mathrm{F}(12 \%)$, followed by $\mathrm{W}(3.5 \%)$ and $\mathrm{C}(2.2 \%)$, whereas $\mathrm{M}$ and $\mathrm{S}$ explained less than $2 \%$ of the phenotypic variance. Proportions did not change when the genomic effect was included in the model $(12,3.5$, and $1.9 \%$ for $\mathrm{F}, \mathrm{W}$, and $\mathrm{C}$, respectively). When $\mathrm{G} \times \mathrm{E}$ was included, the proportion attributable to the environmental components decreased slightly in models that included $\mathrm{F}(4 \%)$, increased in models including W $(5.6 \%)$ and remained unchanged in all other models. The $\mathrm{G} \times \mathrm{E}$ accounted for $31 \%$ of the total variance in $\mathrm{G} \times \mathrm{C}$. When defined as $\mathrm{G} \times \mathrm{F}, \mathrm{G} \times \mathrm{M}$, and $\mathrm{G}$ $\times \mathrm{W}$, genotype by environment accounted for 20,14 , and $6 \%$ of the overall variation, respectively. For SCS, the strongest environmental effect was found in models that considered $\mathrm{W}(55 \%)$, followed by $\mathrm{F}(5 \%)$ and $\mathrm{C}$ (4\%), whereas negligible effects were found for M and S. The effect of $\mathrm{W}$ decreased to $35 \%$ when genomic effect was included. Genotype by environment was strongest when fitted as $\mathrm{G} \times \mathrm{C}(17 \%)$, followed by $\mathrm{G} \times \mathrm{M}(12 \%)$, $\mathrm{G} \times \mathrm{S}(11 \%), \mathrm{G} \times \mathrm{F}(10 \%)$, and $\mathrm{G} \times \mathrm{W}(1.5 \%)$. Fat and protein percentages results were similar, with the largest environmental component explained by $\mathrm{W}$ (7 and $6 \%$ for $\mathrm{FP}$ and $\mathrm{PP}$, respectively), and all the other environmental effects explaining less than $2 \%$ for both traits.

Traits Characterization. In the present study $\mathrm{G} \times$ $\mathrm{E}$ components were found to be generally small for FP, almost null for PP, and moderate for SCS. Regarding SCS, environmental effects accounted for a substantial amount of the total variation. Large $\mathrm{G} \times \mathrm{E}$ components were estimated for MY, with some scenarios where the proportion of variation estimated for the interaction was larger than the one for the genomic effect itself.

Erosion of the Genomic Effect when Interaction with Environment Was Included. When included, $\mathrm{G} \times \mathrm{E}$ partially eroded both genomic and environmental effects, but with different magnitude across traits and models. Across all 4 traits, accounting for the $\mathrm{G} \times \mathrm{E}$ eroded up to $50 \%$ of the genomic variance in the model with $G \times R$. In contrast, the environmental variance was only slightly modified. In $\mathrm{G} \times \mathrm{L}$ models, both genomic and environmental variances estimates decreased, with more emphasis on the former for MY, $\mathrm{PP}$, and SCS. Finally, the interaction term took a large part of the genomic variance for MY in models $\mathrm{G} \times \mathrm{S}$ and $\mathrm{G} \times \mathrm{C}$. The results outlined seem to suggest that a portion of what is commonly considered genomic variance could at least in part be attributed to $\mathrm{G} \times \mathrm{E}$ that is not accounted for.

Environment. For the majority of traits, $\mathrm{H}$ was the strongest among environmental effects. This shows that, with a few exceptions, clustering herds by geographical coordinates or region or by using EnCov cannot account for the total variation between herds. The only exception was for SCS and models that included W, where the climate EnCov absorbed a higher proportion of variance than the herd permanent environmental effect $\mathrm{H}$, suggesting that udder infection are potentially (partially) driven by temperature and moisture conditions. Environmental variance estimates of moderate size were also found for W for MY, FP, and $\mathrm{PP}$, suggesting that climate will affect milk production and composition, probably acting as a result of heat stress (Bohmanova et al., 2008). This is also supported by the null estimate of $\mathrm{L}$, reflecting the fact that heat stress is to some extent a seasonal rather than a regional concern. A sizable effect of the herd reproductive performance (as described by EnCov in F) was found on MY, confirming the existing relationship between fertility and milk production (Lucy, 2001; Windig et al., 2006).

Genomic by Environment Interaction. In the present study, the $\mathrm{G} \times \mathrm{E}$ contribution was always nonnull (i.e., accounting for more than $2 \%$ of phenotypic variance) and in some cases stronger than the respective environmental effect. The only exception was when considering the environment as defined by $\mathrm{H}$, which always gave null estimates probably as consequence of the small size of sire by herd blocks (5,401 levels with median size of the block of 3 hysDYD). When we used $\mathrm{R}$ to define the environments, the proportion of environmental variation was always smaller compared with $\mathrm{H}$, but $\mathrm{G} \times \mathrm{E}$ was always appreciable. Geographical location covariates of the herd seemed to be a good equivalent to using the region as a blocking factor, as $\mathrm{G} \times \mathrm{L}$ accounted for almost all variation due to $\mathrm{G} \times \mathrm{R}$ for PP and SCS and partially for MY and FP. We can speculate that there will be reranking of sires across regions, given the sum of all environmental conditions (i.e., climate and management) that the cows could face if reared in different regions across the country. The same conclusions were drawn by Tsuruta et al. (2015), who found MY to be regulated by a slightly different genetic architecture across regions of the United States.

Genomic by climate interaction was small but present for MY, yet negligible for all other traits, suggesting that the milk production will be the most sensitive trait to changing environmental conditions. This is in agree- 
ment with Zwald et al. (2003), who estimated less than unity genetic correlations for MY between environments with extreme maximum monthly temperature values. Ravagnolo and Misztal (2000) also found genetic variation on MY for the reaction norm on the heat-humidity index of Holstein cows raised in Georgia, pointing out that the different genetic potential to cope with heat stress is expressed only above a certain threshold of heat-humidity index.

Genomic by management interaction significantly affected all traits. Estimates obtained through $\mathrm{G} \times \mathrm{M}$ and $\mathrm{G} \times \mathrm{F}$ were moderate for MY and SCS, and small for FP and PP. On the other hand, $G \times S$ and $G \times$ $\mathrm{C}$ had moderate effect on MY, SCS, and FP but were negligible on PP. The EnCov that we used were able to describe the environments in which the $\mathrm{G} \times \mathrm{E}$ can be observed, and some were also found relevant in other studies, such as calving interval (Calus and Veerkamp, 2003), herd size (Fikse et al., 2003; Zwald et al., 2003), and sire genetic merit (Zwald et al., 2003).

In the present study, we defined the farm productive and reproductive levels using herd-level parameters. We found that $G \times E$ effects were stronger than their respective environmental effect. Although some confounding between sires and environments could have occurred despite the data editing, these results suggest that the farming environment would affect cows with different genetic background more than how it would affect the entire herd. Moreover, for MY, the $\mathrm{G} \times \mathrm{E}$ variance estimate was in some case larger than the genomic variance. Present results could be valuable in a precision-mating framework, where farmers could take into account herd parameters in the choice of genetic material.

\section{Predictive Ability Including Genotype by Environment Interaction}

New and Progeny Testing Bulls. Predictive ability of the models for new and progeny test bulls is reported in Figure 3 and Supplemental Table S3 (https://doi.org/10.3168/jds.2016-11543) and are expressed on a 0 to 100 scale. Figures report histograms that indicate prediction accuracy as averaged over the 4 folds with standard error bars and the dashed line representing the performance of the reference model that is also reported on the left-hand column. It should be noted that we considered a predictand that includes genomic, environmental and residual variation, thus it is expected that prediction accuracies will be lower than what would commonly found in dairy cattle genomic prediction that uses deregressed breeding values as predictand. For each model, accuracy over the 4 folds was averaged and the standard deviation was computed; if the zero value was included within 1 standard deviation unit from the average over the folds, that model was not be discussed.

For the new bulls scenario, accuracies were low in general and mostly null for MY. Models that accounted only for the genomic effect gave prediction accuracies of 13.0 for FP, 24.6 for PP, 10.2 for SCS, and 10.0 for MY. All the other models gave equivalent results, with the only exception of $\mathrm{G} \times \mathrm{W}$, which exceeded the other models for FP, PP, and MY (29.8, 47.9, and 16.5, respectively).

In the incomplete progeny test scenario, models that included only a genomic effect yielded non-null accuracies for FP, PP, and SCS only (24.7, 26.0, and 22.3, respectively). Other models gave equivalent prediction accuracies for SCS, so that no model performed significantly better that the reference for this trait. Accounting for $\mathrm{G} \times \mathrm{W}$ again increased accuracies for FP (45.6), PP (59.8), and MY (21.4).

In the 2 cross-validation scenarios described, models that accounted for $G \times E$ seldom performed better than the simple $G$ model. An exception was for $G \times$ $\mathrm{W}$, which always performed better than the other models (except for SCS). Results are supporting evidence that climatic EnCov can be valuable to characterize the different reaction of the genotypes to environmental changes.

New Environmental Conditions. Figure 4 (and Supplemental Table S3; https://doi.org/10.3168/ jds.2016-11543) reports the predictive ability for the missing region scenario. The reference model always had non-null prediction accuracies, with values of 20.6, 29.8, 35.9, and 26.7 for MY, FP, PP, and SCS, respectively. Alternative models performed similarly to the reference with the exception of $\mathrm{G} \times \mathrm{W}$ for $\mathrm{FP}$ and $\mathrm{PP}$ (38.1 and 50.9, respectively) and $\mathrm{G} \times \mathrm{H}$ for MY (26.9). Again, models with $\mathrm{G} \times \mathrm{W}$ were shown to be valuable alternatives to the reference model for the milk composition traits.

When predicting the Southeast region (Figure 5), no models performed better than the reference for MY (22.3), but $\mathrm{G} \times \mathrm{W}$ improved predictions for all other traits (35.6 vs. 29.3 for FP, 50.3 vs. 39.6 for PP, 28.2 vs. 24.3 for SCS). In addition, $\mathrm{G} \times \mathrm{H}$ increased accuracies for SCS (32.5). Predicting the Southwest region, accuracies for the reference model were 16.2, 26.0, 38.5, and 33.4 for MY, FP, PP, and SCS, respectively. The best performing model for MY was $\mathrm{G} \times \mathrm{H}$ (28.1), followed by $\mathrm{G} \times \mathrm{W}$ (25.3). In summary, no models performed better than the reference for SCS, $\mathrm{G} \times \mathrm{H}$ was best the performing model for FP (29.2), and $\mathrm{G} \times$ $\mathrm{W}$ increased prediction accuracy for PP (50.6). Again, for this cross-validation scenario, it was not possible to find a specific set of EnCov that consistently provided 
TIEZZI ET AL.
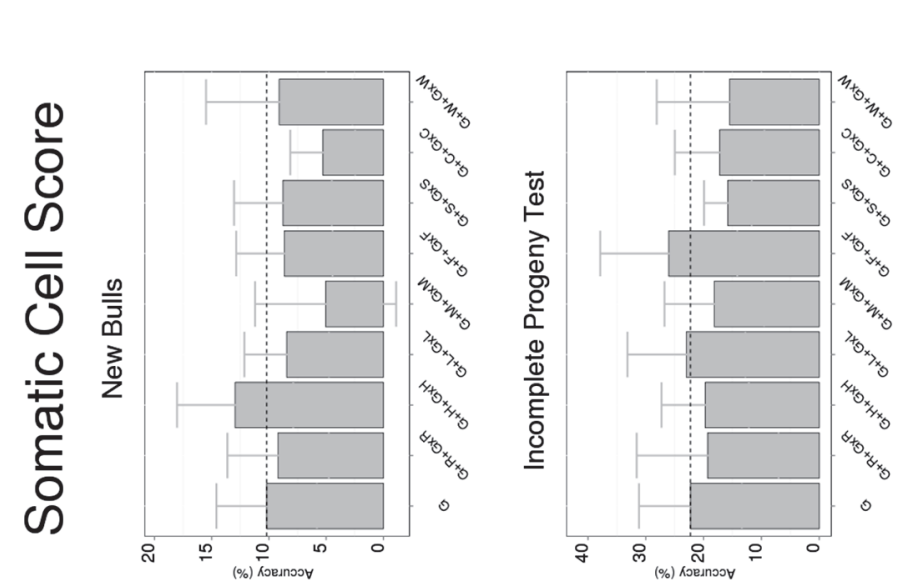

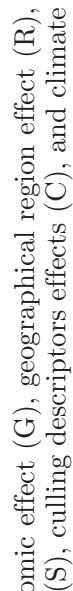
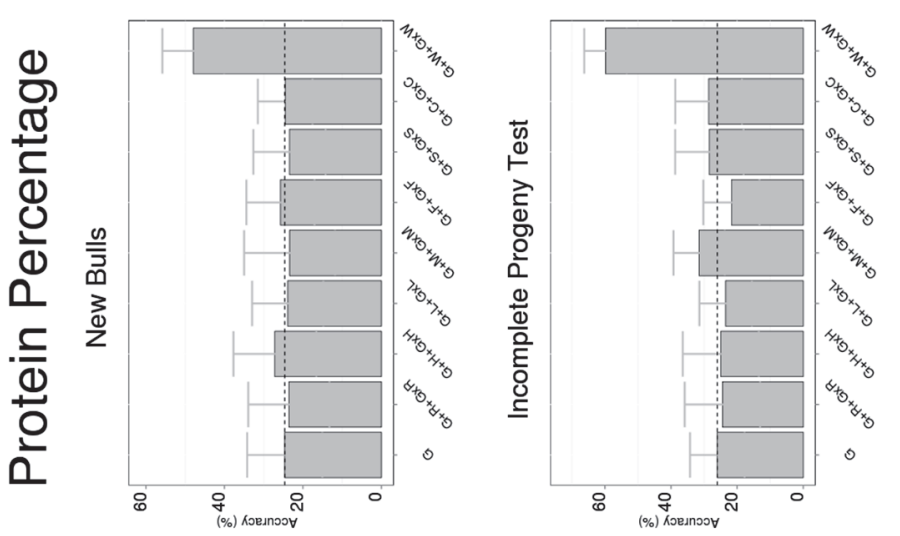

递量
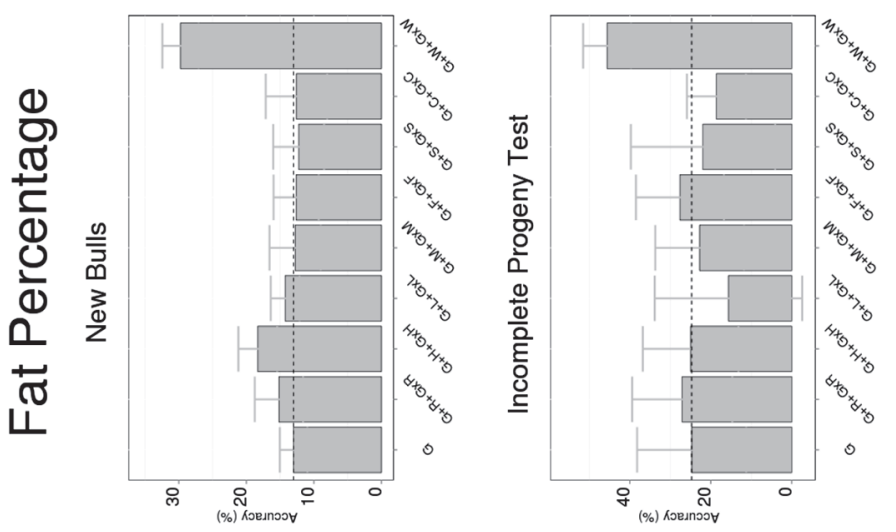

速

.

$\frac{\sqrt[3]{8}}{8}$

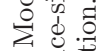

密:

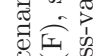

in

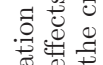

氜: 专

点焉

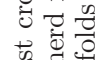

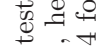

实焉

200

离

눌

द्व

要

暳

青总

羊它
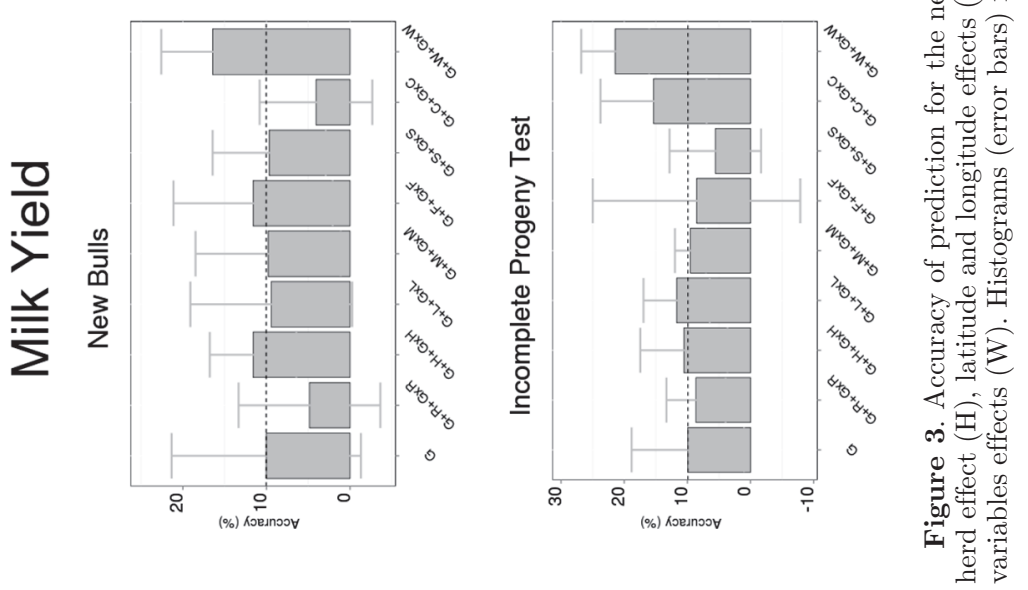

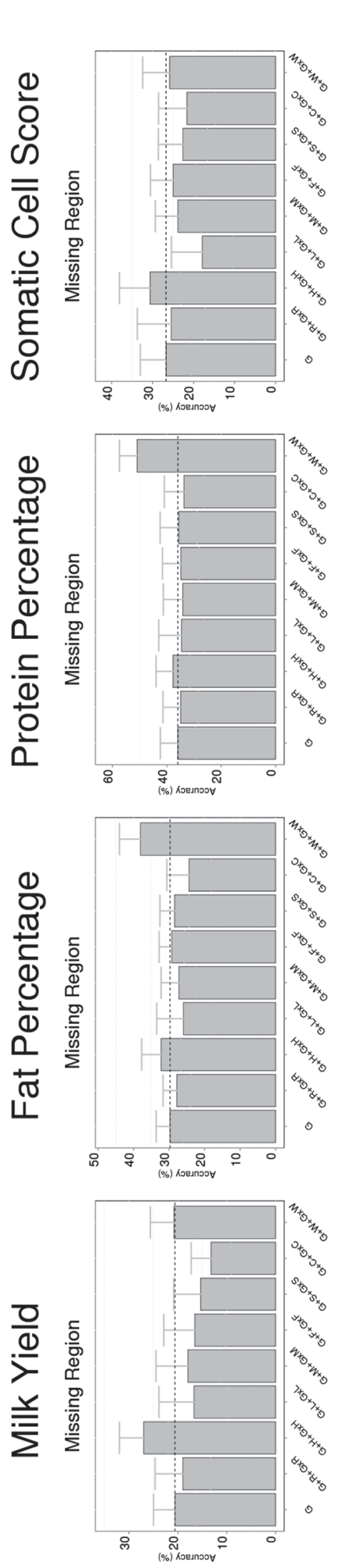

better performance than the reference model, but on 2 of the 4 traits $\mathrm{G} \times \mathrm{W}$ was able to increase accuracy compared with the genomic only model.

\section{On the Inclusion of Genomic by Environment Interaction in Genomic Prediction}

To the best of our knowledge, no study comparable to the current study is available in dairy cattle breeding literature. On a similar subject, Wright and VanRaden (2015) analyzed total lactation milk yield on US Holsteins using random-regression models with reaction norm on temperature-humidity index and herd productive level, but an advantage over the reference model was negligible. Random regression reaction norm models have been used in prediction of performance under different environmental conditions in other livestock species. In beef cattle, Mota et al. (2016) compared these models to the traditional animal models for predicting tick resistance, but no advantage was found in modeling G $\times$ E. On the other hand, Silva et al. (2014) found a clear advantage in modeling $\mathrm{G} \times \mathrm{E}$ for the prediction of number of piglets born in a multicountry swine population. The same methodology used in the present study was previously tested on wheat data sets by Jarquín et al. (2014) and Lopez-Cruz et al. (2015) and on a cotton data set by Pérez-Rodrìguez et al. (2015). In all cases, models that accounted for the G $\times$ E were able to estimate variance components due to this effect as well as to provide better predictive performance than models that neglected it. In the present study, we confirm that the methodology is reliable for the analysis of multienvironmental data, either using blocking factors or EnCov. One limitation of our study and the model used stems from not including the heterogeneity of residual variance in the models, which will require further research and model implementation. On most of the scenarios tested, models that included the $\mathrm{G} \times \mathrm{E}$ outperformed models that included only a genomic effect. The most promising set of EnCov appears to be the one including the climate variables, and this could be a consequence of having specified values of climate variables that were HYS-specific, as opposed to the management variables that were herd-specific. In general, the challenge to identify a unique set of covariates capable of describing the entire variety of environments and the specification of these variables with different levels of resolution (herd level vs. herdyear-season level) should be clarified by future research.

\section{CONCLUSIONS}

In the present study we used models that accounted for genotype by environment interaction and genomic 
TIEZZI ET AL.
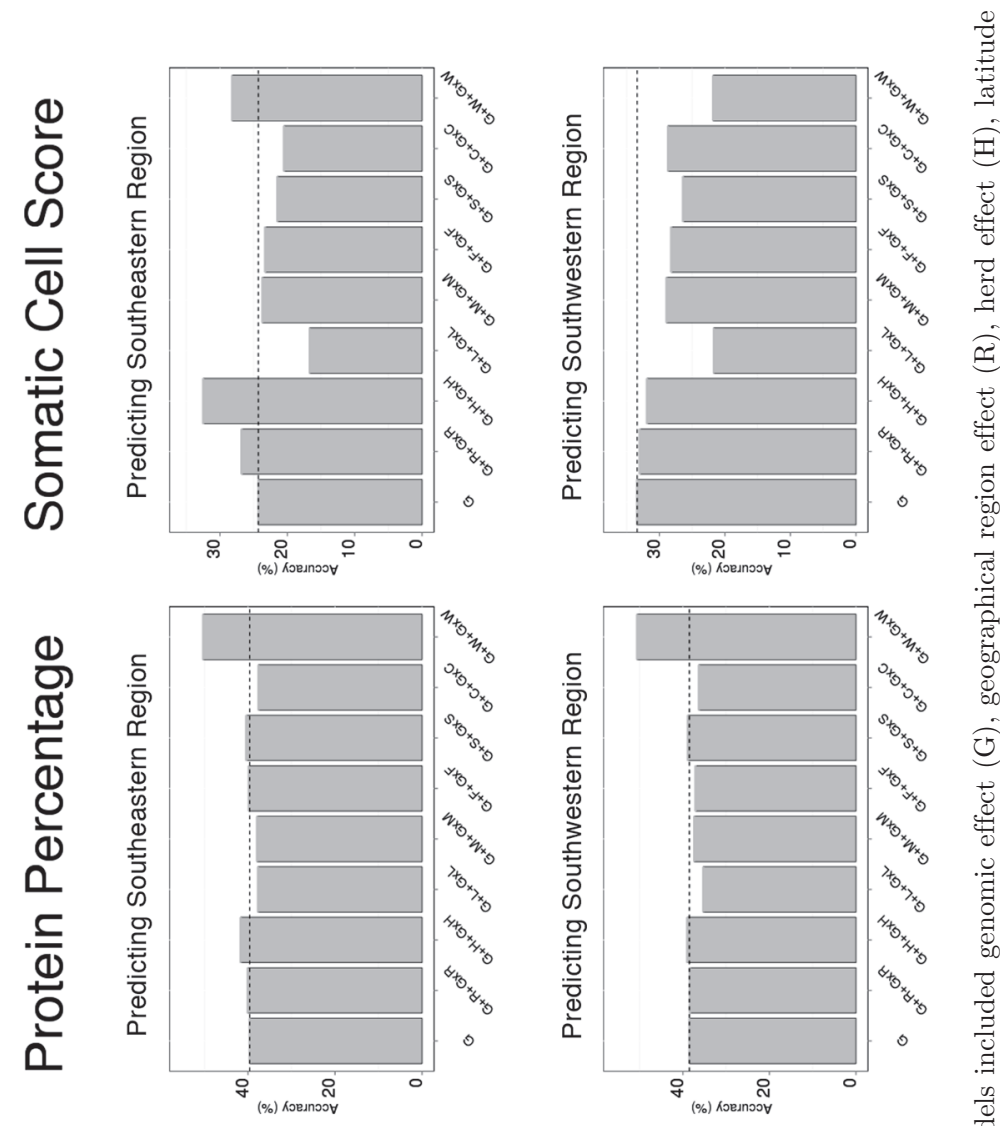

苞䓵

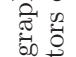
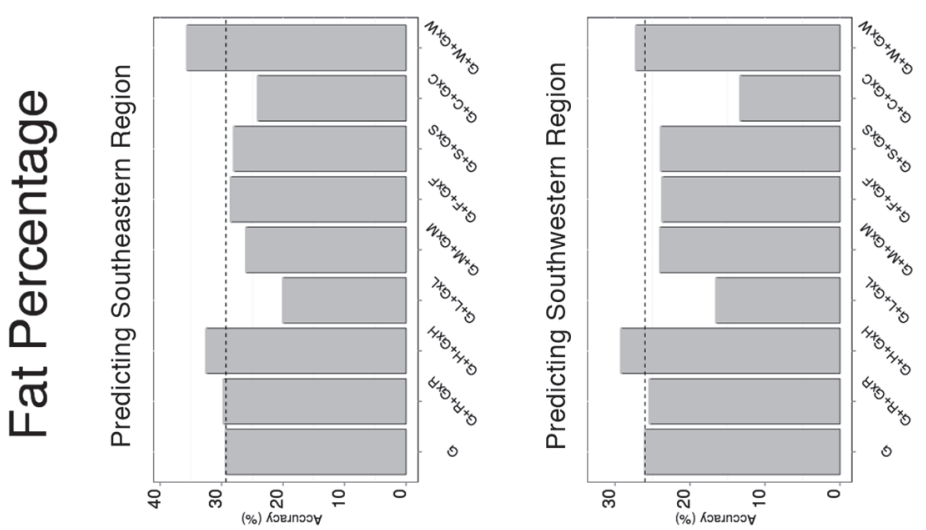

की

苟.

औृ

过

总

过

苛

홍



象密

它庄

동

若造

焉

击

สิ

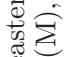

苞雚
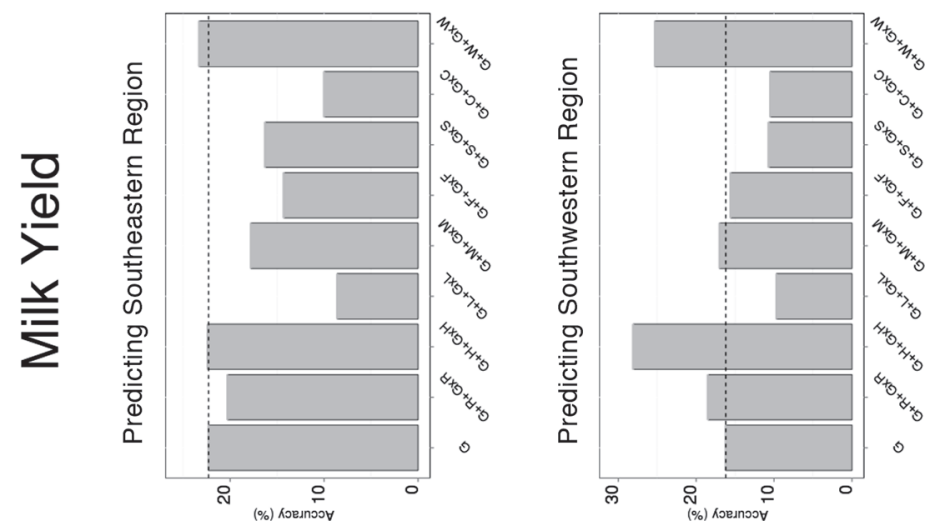

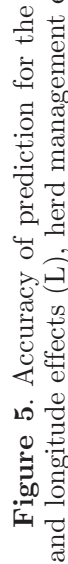


information on dairy productive traits. Environment was defined using several parameters to describe the herd. The magnitude of this interaction was seldom null, and sometimes stronger than the respective environmental effect. This suggests that the farming environment will affect the different strains of cows more than it affects the entire herd. Moreover, the variance explained by the interaction was sizable compared with the variance explained by the genomic effect, suggesting that the performance of a cow carrying a given genotype will substantially differ from farm to farm. Thus, it is confirmed that genetic material that is top performing in a given environment is very unlikely to be top performing in a different environment. Farmers can take advantage of models accounting for genotype by climate interaction in a precision-mating framework. It was not possible to find a unique model consistently giving best performance across all cross-validation scenarios, but results point toward climate variables as good candidates for this purpose. Further research is needed to find further combinations of environmental parameters that can describe the conditions that challenge the productivity of the raised animals.

\section{ACKNOWLEDGMENTS}

The authors thank Dairy Records Management Systems (Raleigh, NC) and the Council on Dairy Cattle Breeding (Reynoldsburg, OH) for providing the data used in this study.

\section{REFERENCES}

Bohmanova, J., I. Misztal, S. Tsuruta, H. D. Norman, and T. J. Lawlor. 2008. Short communication: Genotype by environment interaction due to heat stress. J. Dairy Sci. 91:840-846.

Breen, J. 2012. zipcode: U.S. ZIP Code database for geocoding. R package version 1.0. Accessed Sep. 1, 2015. http://CRAN.Rproject.org/package=zipcode.

Bryant, J., N. López-Villalobos, C. Holmes, and J. E. Pryce. 2005. Simulation modelling of dairy cattle performance based on knowledge of genotype, environment and genotype by environment interactions: Current status. Agric. Syst. 86:121-143.

Bryant, J. R., N. López-Villalobos, J. E. Pryce, C. W. Holmes, and D. L. Johnson. 2006. Reaction norms used to quantify the responses of New Zealand dairy cattle of mixed breeds to nutritional environment. N. Z. J. Agric. Res. 49:371-381.

Calus, M. P., P. Bijma, and R. F. Veerkamp. 2004. Effects of data structure on the estimation of covariance functions to describe genotype by environment interactions in a reaction norm model. Genet. Sel. Evol. 36:489-507.

Calus, M. P., and R. F. Veerkamp. 2003. Estimation of environmental sensitivity of genetic merit for milk production traits using a random regression model. J. Dairy Sci. 86:3756-3764.

Council on Dairy Cattle Breeding. 2016. Bovine genetic trend: Holstein or Red \& White. Accessed May 26, 2016. https://www.cdcb. us/eval/summary/trend.cfm.

de los Campos, G., D. Gianola, and G. J. M. Rosa. 2009. Reproducing kernel Hilbert spaces regression: A general framework for genetic evaluation. J. Anim. Sci. 87:1883-1887.
Falconer, D. S. 1990. Selection in different environments: effects on environmental sensitivity (reaction norm) and on mean performance. Genet. Res. 56:57-70.

Fikse, W. F., and G. Banos. 2001. Weighting factors of sire daughter information in international genetic evaluations. J. Dairy Sci. 84:1759-1767.

Fikse, W. F., R. Rekaya, and K. A. Weigel. 2003. Genotype $\times$ environment interaction for milk production in Guernsey cattle. J. Dairy Sci. 86:1821-1827.

Gianola, D., and J. B. van Kaam. 2008. Reproducing kernel Hilbert spaces regression methods for genomic assisted prediction of quantitative traits. Genetics 178:2289-2303.

Hayes, B. J., P. J. Bowman, A. J. Chamberlain, K. Savin, C. P. Van Tassell, T. Sonstegard, and M. E. Goddard. 2009. A validated genome wide association study to breed cattle adapted to an environment altered by climate change. PLoS One 4:e6676.

Hijmans, R. J., E. Williams, and C. Vennes. 2012. geosphere: Spherical Trigonometry. R package version 1.2-28. Accessed Sep. 1, 2015. https://cran.r-project.org/web/packages/geosphere/index.html.

Janss, L., G. de Los Campos, N. Sheehan, and D. Sorensen. 2012. Inferences from genomic models in stratified populations. Genetics 192:693-704.

Jarquín, D., J. Crossa, X. Lacaze, P. Du Cheyron, J. Daucourt, J. Lorgeou, F. Piraux, L. Guerreiro, P. Pérez, M. Calus, J. Burgueno, and G. de los Campos. 2014. A reaction norm model for genomic selection using high-dimensional genomic and environmental data. Theor. Appl. Genet. 127:595-607.

Kassen, R. 2002. The experimental evolution of specialists, generalists, and the maintenance of diversity. J. Evol. Biol. 15:173-190.

Kolmodin, R., and P. Bijma. 2004. Response to mass selection when the genotype by environment interaction is modelled as a linear reaction norm. Genet. Sel. Evol. 36:435-454.

Kolmodin, R., E. Strandberg, H. Jorjani, and B. Danell. 2003. Selection in the presence of a genotype by environment interaction: Response in environmental sensitivity. Anim. Sci. 76:375-386.

Kühn, C., G. Thaller, A. Winter, O. R. Bininda-Emonds, B. Kaupe, G. Erhardt, J. Bennewitz, M. Schwerin, and R. Fries. 2004. Evidence for multiple alleles at the DGAT1 locus better explains a quantitative trait locus with major effect on milk fat content in cattle. Genetics 167:1873-1881.

Lopez-Cruz, M., J. Crossa, D. Bonnett, S. Dreisigacker, J. Poland, J. L. Jannink, R. P. Singh, E. Autrique, and G. de los Campos. 2015. Increased prediction accuracy in wheat breeding trials using a marker $\times$ environment interaction genomic selection model. G3 (Bethesda) 5:569-582.

Lucy, M. C. 2001. Reproductive loss in high-producing dairy cattle: Where will it end? J. Dairy Sci. 84:1277-1293.

Misztal, I., S. Tsuruta, T. Strabel, B. Auvray, T. Druet, and D. H. Lee. 2002. BLUPF90 and related programs (BGF90). Pages 21-22 in Proc. 7th World Congr. Genet. Appl. to Livest. Prod. Montpellier, France.

Mota, R. R., P. S. Lopes, R. J. Tempelman, F. F. Silva, I. Aguilar, C. C. G. Gomes, and F. Cardoso. 2016. Genome-enabled prediction for tick resistance in Hereford and Braford beef cattle via reaction norm models. J. Anim. Sci. 94:1834-1843.

Mulder, H. A., R. F. Veerkamp, B. J. Ducro, J. A. M. van Arendonk, and P. Bijma. 2006. Optimization of dairy cattle breeding programs for different environments with genotype by environment interactions. J. Dairy Sci. 89:1740-1752.

Nilforooshan, M. A., J. H. Jakobsen, W. F. Fikse, B. Berglund, and H. Jorjani. 2010. Application of a multiple-trait, multiple-country genetic evaluation model for female fertility traits. J. Dairy Sci. 93:5977-5986.

Nilforooshan, M. A., J. H. Jakobsen, W. F. Fikse, B. Berglund, and H. Jorjani. 2014. Multiple-trait multiple-country genetic evaluation of Holstein bulls for female fertility and milk production traits. Animal 8:887-894.

Parker Gaddis, K. L., J. B. Cole, J. S. Clay, and C. Maltecca. 2016. Benchmarking dairy herd health status using routinely recorded herd summary data. J. Dairy Sci. 99:1298-1314. 
Pérez, P., and G. de los Campos. 2014. Genome-wide regression \& prediction with the BGLR statistical package. Genetics 198:483-195.

Pérez-Rodriguez, P., J. Crossa, K. Bondalapati, G. De Meyer, F. Pita, and G. Campos. 2015. A pedigree-based reaction norm model for prediction of cotton yield in multienvironment trials. Crop Sci. 55:1143-1151.

Plummer, M., N. Best, K. Cowles, and K. Vines. 2006. CODA: Convergence diagnosis and output analysis for MCMC. R News 6:7-11.

Ravagnolo, O., and I. Misztal. 2000. Genetic component of heat stress in dairy cattle, parameter estimation. J. Dairy Sci. 83:2126-2130.

R Core Team. 2016. R: A language and environment for statistical computing. R Foundation for Statistical Computing, Vienna, Austria. https: //www.R-project.org/.

Schaeffer, L. R. 1994. Multiple-country comparison of dairy sires. J. Dairy Sci. 77:2671-2678.

Shariati, M. M., G. Su, P. Madsen, and D. Sorensen. 2007. Analysis of milk production traits in early lactation using a reaction norm model with unknown covariates. J. Dairy Sci. 90:5759-5766.

Silva, F. F., H. A. Mulder, E. F. Knol, M. S. Lopes, S. E. F. Guimarães, P. S. Lopes, P. K. Mathur, J. M. S. Viana, and J. W. M. Bastiaansen. 2014. Sire evaluation for total number born in pigs using a genomic reaction norms approach. J. Anim. Sci. 92:38253834 .

Strandberg, E., S. Brotherstone, E. Wall, and M. P. Coffey. 2009. Genotype by environment interaction for first-lactation female fertility traits in UK dairy cattle. J. Dairy Sci. 92:3437-3446.
Su, G., P. Madsen, and M. S. Lund. 2009. Reaction norm model with unknown environmental covariate to analyze heterosis by environment interaction. J. Dairy Sci. 92:2204-2213.

Tsuruta, S., D. A. L. Lourenco, I. Misztal, and T. Lawlor. 2015. Genotype by environment interactions on culling rates and 305-day milk yield of Holstein cows in 3 US regions. J. Dairy Sci. 98:5796-5805.

VanRaden, P. M. 2008. Efficient methods to compute genomic predictions. J. Dairy Sci. 91:4414-4423.

VanRaden, P. M., C. P. Van Tassell, G. R. Wiggans, T. S. Sonstegard, R. D. Schnabel, J. F. Taylor, and F. S. Schenkel. 2009. Invited review: Reliability of genomic predictions for North American Holstein bulls. J. Dairy Sci. 92:16-24.

Windig, J. J., M. P. L. Calus, B. Beerda, and R. F. Veerkamp. 2006 Genetic correlations between milk production and health and fertility depending on herd environment. J. Dairy Sci. 89:1765-1775.

Windig, J. J., H. A. Mulder, D. I. Bohthe-Wilhelmus, and R. F. Veerkamp. 2011. Simultaneous estimation of genotype by environment interaction accounting for discrete and continuous environmental descriptors in Irish dairy cattle. J. Dairy Sci. 94:3137-3147.

Wright, J. R., and P. M. VanRaden. 2015. Genetic interactions for heat stress and herd yield level: Predicting foreign genetic merit from domestic data. J. Dairy Sci. 98(E-Suppl. 1):350. (Abstr.)

Zwald, N. R., K. A. Weigel, W. F. Fikse, and R. Rekaya. 2003. Identification of factors that cause genotype by environment interaction between herds of Holstein cattle in seventeen countries. J. Dairy Sci. 86:1009-1018. 